\title{
A Fuzzy Group Decision-making Model for Determining the Most Influential Persons in the Sustainable Prevention of Accidents in the Construction SMEs
}

\author{
Z. Turskis, S. Dzitac, A. Stankiuviene, R. Šukys
}

\author{
Zenonas Turskis \\ Faculty of Civil Engineering \\ Vilnius Gediminas Technical University \\ Sauletekio al. 11, Vilnius, Lithuania, 10223 \\ zenonas.turskis@vgtu.lt \\ Simona Dzitac \\ University of Oradea \\ Universitatii, 1, Oradea, Romania, 410087 \\ simona@dzitac.ro \\ Aušra Stankiuviene*, Ritoldas Šukys \\ Faculty of Civil Engineering \\ Vilnius Gediminas Technical University \\ Sauletekio al. 11, Vilnius, Lithuania, 10223 \\ *Corresponding author: ausra.stankiuviene@vgtu.lt \\ ritoldas.sukys@vgtu.lt
}

\begin{abstract}
Safety in the sustainable construction is a game with uncertain reality, with human's life. Managers in power, involved in the construction project life cycle, create rules for the game and are the main players. The project's success can be perceived differently by stakeholders. A company's competitiveness, successful implementation of the projects and effective safety management depends on the strategic allocation of its human resources in order to select a proper project team in alignment with employee capabilities. This requires detailed factors reflecting their role (in line with their interests and attitudes) and knowing which of them has a decisive influence on the successful implementation of the project. The real data describing key factors in this concept can be provided as uncertain conditions. This work presents a novel integrated modified fuzzy group decision-making approach to select and rank the most influential persons ensuring the sustainable prevention of accidents at work in the small and medium-sized construction enterprises. This model includes the Delphi method and fuzzy extensions of Eckenrode's criteria rating method. The proposed model could be expanded in order to select the most suitable individuals for sustainable management of safety and, moreover, for the effective implementation of safety and health measures.
\end{abstract}

Keywords: construction site, accidents prevention, occupational safety, risk management, fuzzy, rating, group, MCDM.

\section{Introduction}

Sustainability is defined as a condition of equilibrium, stability, and interoperability, enabling people to meet their needs and support ecosystems [42]. The application of sustainability principles in any activity, including the construction, is becoming increasingly important for the development in terms of economic, social effectiveness, safety, and sustainability [1]. The uncertain challenges affect planning and practices [17]. A growth in the construction industry creates a demand for suitable materials and techniques [70]. The construction integrates the 
achievements of the various fields of science, and proper safety management is inseparable [27]. In the modern world buildings and infrastructures are becoming increasingly complex [47]. The construction sustainability, safety culture and zero accidents at work aspiration are challenges of crucial importance for modern society. Knowledge and education, to enhance understanding and adaptation of these paradigms, are fundamental to solving these dilemmas $[6,19]$ widespread in organizations even nowadays when many organizations work on several complex projects at the same time [47]. Project leaders control many risks and disadvantages during of construction works and play different roles in safety management in the construction process. A successful implementation of sustainable projects and effective implementation of safety management are the characteristics of a company's competitiveness in the market [74] and reduce environmental, social and economic losses [31]. Consequently, effectiveness of safety management has become a core topic for researches.

The construction industry is one of the most dangerous sectors of the economy. During the last decade, the number of accidents at work has increased. The small and medium-sized enterprises (SMEs) have a higher accidents risk compared to large construction enterprises $[25$, 53]. The increased number of accidents at work in the construction impacts on a sustainable working environment. A reduction of accidents at work, as a priority, must be included in the action plans of construction projects [41]. Hasle et al. [23] has investigated SMEs accidents causation criterion and prevention actions, and concluded that the owners of SMEs may deal with safety and health issues quite differently compared to those in the large construction enterprises.

Many factors influencing accidents at work in the construction are still largely unexplained. In general, accidents at the construction sites could be qualified as defects of the safety management system which occur due to the number of aspects, including technical, technological, organisational and other types of factors which affect human safety performance and working environment $[33,34,52]$. Indrees et al. [26] presented that psychological factors such as an attitude of workers, a workload, organizational relationships, a clarity of roles, a mental stress, job insecurity, and job satisfaction strongly affect workers' safety. Scientists and practitioners mainly concentrated on a risk assessment process $[4,56,59]$.

Dozens of researchers concentrate on reactive (accident frequency and the seriousness index) [53] and proactive indicators (organisational, technical and behavioural), and each of them has their strengths and weaknesses for the safety performance $[24,36,39,43,45,60]$. Yau [66] and Zhou et al. [76] presented that the development of a safety culture significantly reduced the number of accidents. After reviewing the literature, it can be concluded that most of the accidents at work in SMEs construction sites are essentially related to negligent management or insufficient employee safety awareness [67]. Management problems are mainly due to inappropriate management skills, lack of opportunities to implement safety and health strategies, non-compliance with labour safety laws and regulations, and the inappropriate use of security measures [33, 58].

According to Pasman et al. [46], a prediction what could happen under specified conditions is the most elementary step to the better safety.

Meanwhile, it is evident that accidents at work in the construction is a result of behaviour of stakeholders (owners, developer, project leaders, contractors, subcontractors, occupational safety and health (OSH) specialists, OSH coordinators). Therefore, the stakeholders must understand principles of the sustainable construction and the impact of safety. The selection, preparation, and implementation of the right strategies for effective prevention of accidents is the biggest challenge for the most enterprises [18]. Therefore, it is very important to know which is the most influential person and which person can continuously improve the level of safety, ensure a sustainable and proper prevention of accident at work in construction.

Until now, there is a lack of research on who the main stakeholders on onsite construction are and how they influence the effective safety on SME's construction site. This research examines 
the understanding of the role of stakeholders and their importance in ensuring the management of accident prevention in projects. Therefore, all stakeholders need to be identified, categorized and their concerns, interests and influence need to be analysed and prioritized using group fuzzy model.

The authors consider that this work presents a useful approach to the accidents prevention in the construction, and suggest a novel integrated group fuzzy modified approach to determine the most influential person in the prevention of accidents at work in the SME's. This model integrates the Delphi technique and a modified fuzzy extension of Eckenrode's rating method. The presented model will be expanded and applied for the sustainable construction project development and the ranking of the main persons for preparation and implementation of a proper safety prevention projects.

\section{Fuzzy MCDM safety management problems' solution models in construction site}

A successful project is considered when all risks are properly managed in all project stages. The selection of proper techniques and strategies depends on all players involved in construction project implementation. The project's owner, project manager, project OSH coordinator, contractor, subcontractor, OSH coordinator, OSH specialist are examples of stakeholders that are influential persons in accidents prevention during the design and organization of the project. Stakeholders must constantly seek and promote their mutual interests in reducing any risks and improving their management skills. It should be emphasized that all stakeholders involved in construction project need to be aware of the risks they are facing and how they apply risk management in order to create better working conditions.

Safety in the sustainable construction is a stakeholders' game against nature, environment, and with human's life. The stakeholders and project participants play significant role in this game dealing with problems. The owner or client of the project is the person concerned and has overall responsibility for project management. It is often related to the financial part; while other organizations or individuals interested in the project have contractual relations with the project owner. However, the project owner can transfer management responsibility to other stakeholders in the project. But it is not exempted from liability for the safety and health of workers in accordance with established legislation. The project owner (client) or project manager designates one or more OSH coordinators at the site who coordinate the preparation of a safety and health plan and ensures that site workers apply all the preventive measures they need to take on their safety and health site. In addition, employers or their designated OSH specialist must comply with the minimum safety and health requirements applicable at construction sites and must take into account the directions of the OSH coordinator.

It is obvious that stakeholders, participating in project management and accident prevention, must constantly seek and promote their mutual interests in reducing any risks and improving their management skills. It is important that the project clearly defined the role and influence of stakeholders in preventing accidents. In addition, stakeholders need to be equally guided by the need to manage the threats, opportunities and uncertainties associated with developmental achievements and commit to reaching the desired goal in the relationship. There are direct and indirect reciprocal relations between the participants and the organization or project; because everyone has the ability to influence and can affect other activities. Due to the variety of different stakeholders involved in the project, the risk of conflicts increases, and this can increase the risk associated with the construction project and may affect the successful completion of the project. In the implementation of the project, the co-operation plan of stakeholders can be considered 
A Fuzzy Group Decision-making Model for Determining the

Most Influential Persons in the Sustainable Prevention of

Accidents in the Construction SMEs

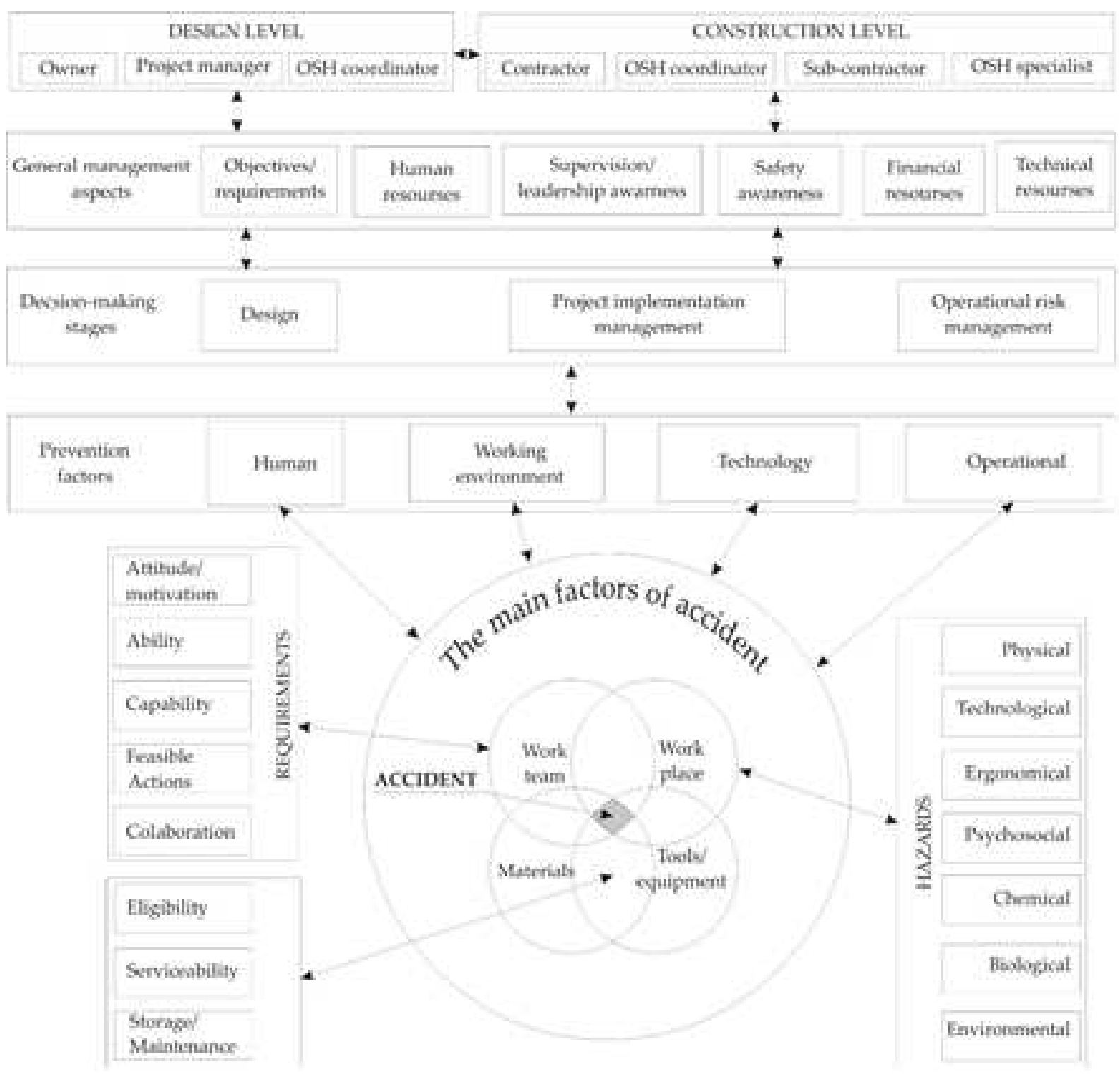

Figure 1: The main influencing factors of accident at work

an important part of overall risk management. The stakeholder input may be beneficial to the project, or, conversely, may jeopardize the success of the project. An assessment of the role of project stakeholders at the initial design stage and the ability to manage unpredictable responses throughout the construction phase are crucial to the success of the project.

The solutions are not completely known, more than half of them are uncertain and insecure. The uncertainty and insecurity arise from many rules which has permanently ordained, and it depends on how many approaches are caused by mental factors, while the solution's implementation in practice without any limitations becomes possible. While the accidents at work cannot be exactly predicted, in general, the solution becomes possible only when risk management is carried out under the current real-life conditions. The problem of measuring according to some criteria in construction is known as multi-criteria decision-making (MCDM) [75]. Whereas there is no method which is the most suitable for all decision-making situations, many MCDM models and their extensions have been developed [40]. A number of authors promote their own MCDM methods and models. However, there is a lack of methods and models of evaluating 
the efficiency of personnel. MCDM methods in the construction can be used on the national, organizational and project levels. Even so, the most assessment methods are trying to find out how to make the most economic construction decisions, and mostly all these decisions are only intended for economic objectives [55]. Therefore, MCDM approaches are very useful to solve different management problems.

A selection of safe and effective management systems in the construction is a complex MCDM task. The Analytic Hierarchy Process (AHP) [49] is the most widely used MCDM method. A lot of studies have been made on MCDM methods and applications. Usually the AHP is applied to calculate significance of criteria. Šaparauskas et al. [51] assessed and prioritised the relative importance of various criteria based on the Saaty's Analytic Hierarchy Process (AHP). A multiplicative exponential weighting (MEW) was applied in order to calculate the best performed project [67]. Keshavarz et al. [29] introduced a new method of Evaluation based on Distance from Average Solution (EDAS) for multi-criteria inventory classification problems. Zavadskas et al. [71] merged two different multi-criteria decision-making (MCDM) methods and developed an original Weighted Aggregated Sum Product assessment method (WASPAS), while the original combination of three different MCDM methods was introduced as a new Multiple Objective Optimisation on the basis of Ratio Analysis Plus Full Multiplicative Form (MULTIMOORA) method.

The similar problems could be solved using different methods. Zavadskas et al. [72] applied three different hybridised well-known MCDM techniques to rank and assess different technological alternatives in construction: Step-Wise Ratio Assessment - Technique for Order of Preference by Similarity to Ideal Solution (SWARA-TOPSIS), ELimination and Choice Expressing the REality (Et Choix Traduisant la REalité (SWARA-ELECTRE III Elimination)), Multicriteria Optimization and Compromise Solution (VIsekriterijumska optimizacija i KOmpromisno Resenje in Serbian language (SWARA-VIKOR)). Recently Turskis and Juodagalvienè [61] presented a novel peculiar model, which is based on ten different multi-criteria decision-making methods: Game Theory, AHP, Simple Additive Weighting (SAW), Multiplicative Exponential Weighting (MEW), TOPSIS, EDAS, Additive Ratio Assessment (ARAS), Full Multiplicative form, Laplace Rule, and Bayes Rule.

A philosophy and logic are the basis of mathematical models of real-life issues. In 1657 Christopher Wren in his chair of astronomy at Gresham College said that mathematical models could be used when dealing with uncertainty [65]. Most of the construction safety management problems includes vague and uncertain values of criteria. The fuzzy set theory provides a decision framework to incorporate imprecise judgments inherent in the personnel selection process. In 1965 Zadeh [69] introduced the fuzzy set theory to deal with inaccurate and uncertain data, even in situations when information is based on subjective evaluations and defined in the lexical conditions. Zadeh used fuzzy set theory to a gradual transition from one class to another in the development of decision support models. It was later applied in MCDM applications $[8,32]$. Risk management decision determined by various fuzzy criteria and used by practitioners and supervisors in the construction sector [10]. The fuzzy set theory and fuzzy extensions of multicriteria decision-making models play principal roles in the risks' weighting, responses and choices of means to manage them $[15,20]$.

The group decision-making processes are necessary to design and evaluate a set of different alternatives. One of the most important task is to reject those alternatives that do not meet lower bounds of the significant criteria values. For a long time, a rigorous agreement was seen as a final group's opinion. In the most cases, a group of experts who make real-life decisions have no strict and steady opinion about the same criteria and alternatives. An agreement of the group reached when the most dominant players agree with the criteria ratings and performances of the considered alternatives. Real-life problems' modelling and solution lead the group of 
decision-makers to situations when models are based on vague logic. In addition, most often the models based on the criteria rating in words. Such type of ratings cannot be replaced by the strict (crisp) numerical values. Fuzzy set theory allows decision makers to use incomplete or partially obtained information into the problem solving model [62]. A fuzzy set is characterized by a membership (characteristic) function which assigns to each object a grade of membership ranging [69]. Various types of membership functions are available. In this research the most commonly used triangular membership function is used [14]. A fuzzy triangular number will be denoted as $(\alpha, \beta, \gamma)(\alpha$ - lower value of fuzzy number, $\beta$ - modal value of fuzzy number, $\gamma$ upper value of fuzzy number). Van Laarhoven and Pedrycz [63] introduced the basic operations of fuzzy triangular number.

Many researchers investigated such problems and developed different fuzzy models to solve problems of safety and risk management in the construction. Debnath et al. [12] developed a fuzzy inference model for assessing occupational risks in the construction sites. Grassi et al. [21] presented a fuzzy multi-criteria model for risk evaluation in the workplaces. Liu and Tsai [38] used the fuzzy ANP analysis to identify and assess the underlying hazards and causes.

\section{An integrated Delphic-Eckenrode's Likert-type scale-based fuzzy rating}

It is very important to identify the importance of the activities of the different process managers before starting to assess the key challenges of workplace safety's management, efficiency level of safety solutions and quality improvement. To order to achieve this, experts can use weighting methods for criteria. There are a lot of different subjective approaches for assessing weights [44]: AHP [49], ANP [50] expert method [73], SWARA [28,30], FARE (FActor RElationship) [21], etc.

Nominal group technique Delphi [13,37] is a useful tool solving complicated problems which needs expert data. This is a group decision-making process and includes idea generation, problem description, data assessment, and generation of feasible alternatives.

Five types of measurement scales (nominal, ratio, ordinal, interval, or fuzzy) commonly could be used to measure criteria values and importance [64]. Lot of scales evaluating importance of criteria are proposed in scientific papers. For example, rating of perceived exertion Borg scale [7] is a frequently used quantitative measure of perceived exertion (rated exertion on a scale of 6-20). A data is expected to fit into one or another of the absolute categories. In any case, decision-makers must apply methods appropriate to their data and to the questions they wish to answer. Likert scales were introduced by Likert in 1930s [35] as a tool for the measurement and assessment of attitudes. Since then Likert-type scales have become more popular in many fields of decision-making, including management [57]. It is the most widely used approach to scale responses in survey research. The reason for this is that the Likert scale is a very simple tool to use and can be analysed effectively as interval or fuzzy scales [1]. The Likert-type scale is often used interchangeably with rating scale, even though these two ones are not synonymous.

In 1965 Eckenrode [16] presented seminal work on criteria weights elicitation. The six methods were compared for their reliability and efficiency in collecting the judgment data: Ranking $[2$, 3]; Rating [35]; The Three Paired Comparisons Methods: Partial Paired Comparisons I Buel [9]; Partial Paired Comparisons II; Complete Paired Comparisons [5]; Successive Comparisons Churchman et al. [11,50].

Eckenrode [16] found no significant differences among the techniques. The values calculated by all of methods correlates. Rating is effective for personal assessment, and it's especially effective for group decision making. It works well because it forces expert to get clarity on his 
own criteria and create a shared set of criteria. Eckenrode's Rating method is selected and modified by applying basics of fuzzy sets theory in this study.

The problem solution flow chart is presented in Figure 2.

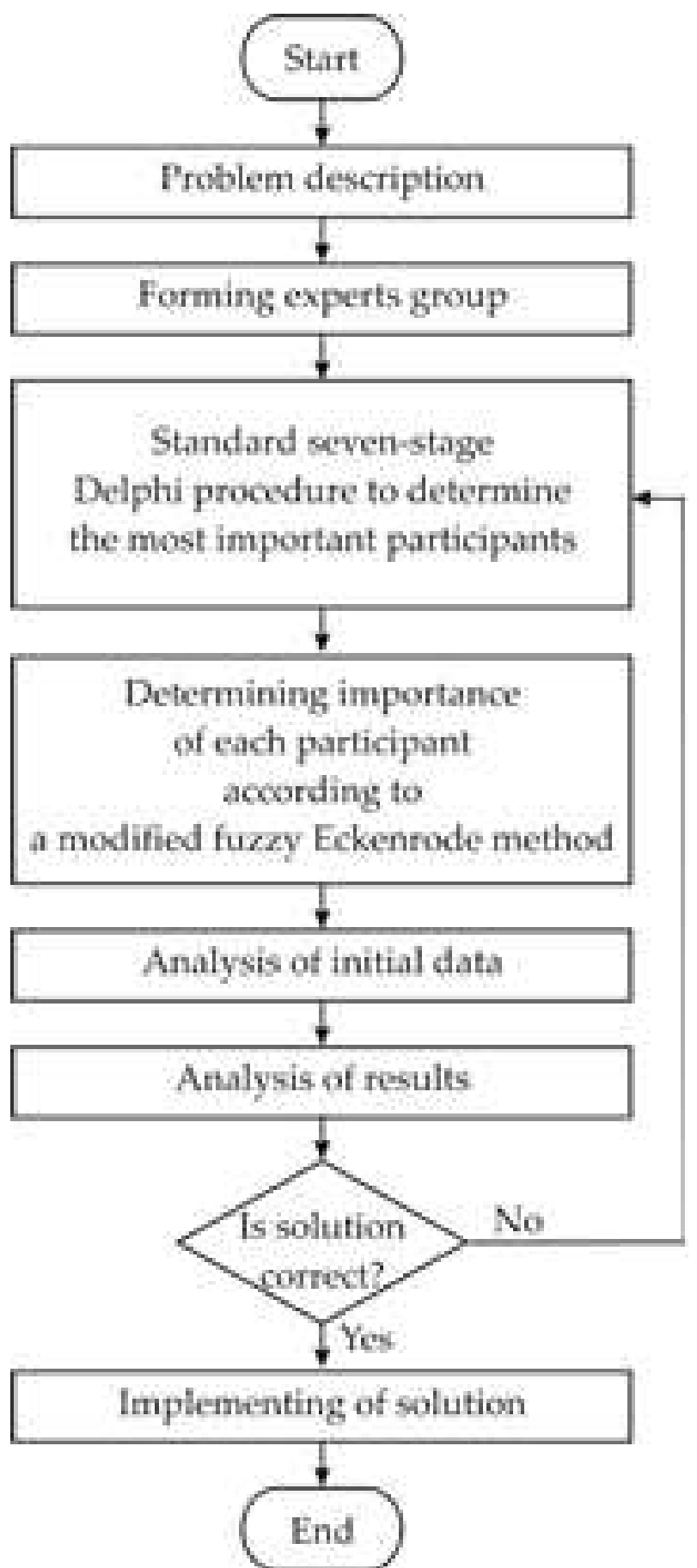

Figure 2: Proposed framework of the study

At the beginning of the problem solution experts determined the main participants (stakeholders) influencing accidents prevention in the construction. Each participant differently affects accidents prevention processes, and therefore has different importance in these problems solving. Delphi method selects the most important stakeholders of the problem under consideration. A 
A Fuzzy Group Decision-making Model for Determining the

Most Influential Persons in the Sustainable Prevention of

Table 1: Likert-type scale to determine participant's importance

$(\mathrm{TFN}=$ Triangular Fuzzy Number $)$

\begin{tabular}{|l|l|l|l|l|l|}
\hline $\begin{array}{l}\text { Importance } \\
\text { abbreviation }\end{array}$ & Value & $\begin{array}{l}\text { Importance } \\
\text { level }\end{array}$ & $\begin{array}{l}\text { TFN } \\
\alpha\end{array}$ & $\begin{array}{l}\text { TFN } \\
\gamma\end{array}$ & $\begin{array}{l}\text { TFN } \\
\beta\end{array}$ \\
\hline $\mathrm{L}$ & 1 & Little & 0.5 & 1 & 1.5 \\
$\mathrm{M}$ & 2 & Medium & 1 & 1.5 & 2 \\
$\mathrm{I}$ & 3 & Important & 1.5 & 2 & 2.5 \\
$\mathrm{~V}$ & 4 & Very & 2 & 2.5 & 3 \\
$\mathrm{E}$ & 5 & Extreme & 2.5 & 3 & 3.5 \\
\hline
\end{tabular}

team of experts determined a set of the most important participants (Table 1). The Likert-type scale (important, irrelevant, ...) made below for the significance of the participant's importance (Fig. 3).

Rating: The raw rating assigned by the judge to each criterion against the scale of 0 to 5 ( 5 most valuable or important) treated as follows (Table 2 and 3):

$$
w_{c j}=p_{c j} / \sum_{c=1}^{m} p_{c j}
$$

where,

$w_{c j}$ - weight computed for criterion $c$ from the rating given by judge $j p_{c j}$ - rating given by judge $j$ to criterion $c$, and $\mathrm{w}_{c}$ is calculated as follows:

$$
w_{c}=\sum_{j=1}^{n} w_{c j} / \sum_{j=1}^{n} \sum_{c=1}^{m} w_{c j}
$$

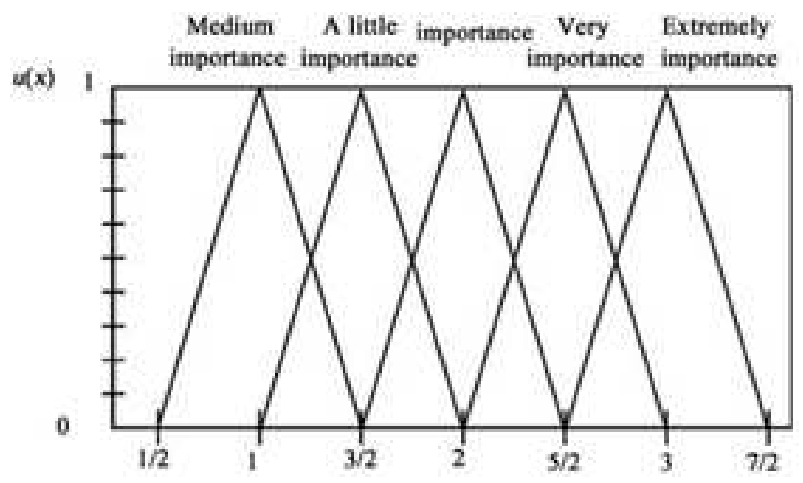

Figure 3: Likert-type scale to determine participant's importance

The equations (1) and (2) using rules of fuzzy arithmetic are modified as follows:

$$
\tilde{w}_{c j}=\tilde{p}_{c j} / \sum_{c=1}^{m} \tilde{p}_{c j}=\left(p_{c \alpha j} / \sum_{c=1}^{m} p_{c \gamma j} ; p_{c \beta j} / \sum_{c=1}^{m} p_{c \beta j} ; p_{c \gamma j} / \sum_{c=1}^{m} p_{c \alpha j}\right) ;
$$

and 


$$
\begin{array}{r}
\tilde{w}_{c}=\left(w_{c \alpha} ; w_{c \beta} ; w_{c \gamma}\right)=\sum_{j=1}^{n} \tilde{w}_{c j} / \sum_{j=1}^{n} \sum_{c=1}^{m} \tilde{w}_{c j}= \\
\left(\sum_{j=1}^{n} w_{c \alpha j} / \sum_{j=1}^{n} \sum_{c=1}^{m} w_{c \gamma j} ; \sum_{j=1}^{n} w_{c \beta j} / \sum_{j=1}^{n} \sum_{c=1}^{m} w_{c \beta j} ; \sum_{j=1}^{n} w_{c \gamma j} / \sum_{j=1}^{n} \sum_{c=1}^{m} w_{c \alpha j}\right)
\end{array}
$$

where,

$w_{j l}-\min _{k} y_{j k}, j=\overline{1, n}, k=\overline{1, p}$ is minimum possible value, $w_{j \alpha}=\left(\prod_{k=1}^{p} y_{j k}\right)^{\frac{1}{p}}, j=$ $\overline{1, n}, k=\overline{1, p}$ is the most possible value and $w_{j \beta}=\max _{k} y_{j k}, j=\overline{1, n}, k=\overline{1, p}$ is the maximal possible value of $j$-th criterion $w_{j \gamma}=\min _{k} y_{j k}, j=\overline{1, n}, k=\overline{1, p}$.

A defuzzification should be applied before final decisions are made. The defuzzification is a process of producing a quantifiable result in crisp logic, given fuzzy logic, and corresponding membership degrees. A common and useful defuzzification technique is a centre of gravity. This method is selected in the case study.

$$
w_{c}=\frac{1}{3}\left(w_{c \alpha}+w_{c \beta}+w_{c \gamma}\right) .
$$

\subsection{Problem solution: Fuzzy group multi-criteria method in assessing the most influential person in sustainable prevention of accidents at work}

In order to ensure sustainable prevention of accidents at work in the construction, stakeholders should use an expert advice which will allow to select the effective and rational alternatives. To achieve the above mentioned goals, an integrated determination method of criteria significance depending on their characteristics, is developed. The problem could be solved based on the survey of experts' data. All of experts have university degree in a civil engineering and actively work with accidents prevention. At first step there was formed a team of eighteen OSH specialists, OSH coordinators, project contractors and subcontractors from different construction companies which employs less 50 people. All of them were male. Respondents were $26-55$ years old (26-30 - 6; 31-35 - 4; 36-40 - 4; 41-45 - 2; 46-50 - 1; 51-55 - 1) and their work experience in the construction was $2-25$ years $(2-5-2 ; 6-10-5 ; 11-15-6 ; 16-20-1 ; 21-25-4)$.

The standard seven-stage Delphi procedure is applied in the case study. Firstly, a facilitator explains to the participants the purpose and procedure of the problem. Secondly, members of the group silently explain their opinion about the solution (criteria), with a short explanation in written not consulting or discussing their ideas with other participants. This ensures that all participants get an opportunity to make an equal contribution. Thirdly, a facilitator encourages a sharing and a discussion of reasons for the choices made (criteria) by each group member to identify a common ground. Fourthly, participants verbally explain in details all presented ideas which are not clear for all participants of the groups or further details about any of the ideas that colleagues have produced and which may not be clear to them. Fifthly, a facilitator eliminates duplicate solutions (criteria) from the list of all solutions, and the members proceed to rank the solutions starting from the most important to the least important. Sixthly, a facilitator involves a prioritizing procedure of the recorded ideas in relation to the original problem. Following the voting and ranking process, a facilitator asks some questions to participants who have a different opinion about ranks from average alternatives (criteria) ranking. Seventhly, a final ranking and rating of alternatives (criteria) should be done.

The participants of experts' group, based on their experience of accidents at work prevention in SME's enterprises, generated as many ideas as they can. The ideas were evaluated against all consequences and sequels factors. Then experts ranked and rated the influential persons in 
A Fuzzy Group Decision-making Model for Determining the

Most Influential Persons in the Sustainable Prevention of

Accidents in the Construction SMEs

Table 2: Participants' importance (PI) lexical evaluation based on Likert-type scale

\begin{tabular}{|c|c|c|c|c|c|c|c|c|c|c|c|c|c|c|c|c|c|c|}
\hline PI & \multicolumn{18}{|c|}{ Experts } \\
\hline & $E_{1}$ & $\mathrm{E}_{2}$ & $E_{3}$ & $\mathrm{E}_{4}$ & $\mathrm{E}_{5}$ & $\mathrm{E}_{6}$ & $E_{7}$ & $\mathrm{E}_{8}$ & $E_{9}$ & $\mathrm{E}_{10}$ & $\mathrm{E}_{11}$ & $\mathrm{E}_{12}$ & $E_{13}$ & $\mathrm{E}_{14}$ & $\mathrm{E}_{15}$ & $\mathrm{E}_{16}$ & $\mathrm{E}_{17}$ & $\mathrm{E}_{18}$ \\
\hline$P_{1}$ & $\mathrm{E}$ & $\mathrm{M}$ & $\mathrm{V}$ & I & $\mathrm{M}$ & $\mathrm{M}$ & $\mathrm{L}$ & $\mathrm{M}$ & $\mathrm{M}$ & $\mathrm{M}$ & $\mathrm{E}$ & I & $\mathrm{E}$ & I & $\mathrm{V}$ & $\mathrm{M}$ & $\mathrm{M}$ & $\mathrm{L}$ \\
\hline$P_{2}$ & $\mathrm{M}$ & L & $\mathrm{L}$ & I & M & I & $\mathrm{M}$ & $\mathrm{V}$ & $\mathrm{L}$ & $\mathrm{M}$ & M & V & I & V & L & I & L & M \\
\hline$P_{3}$ & $\mathrm{E}$ & I & $\mathrm{V}$ & $\mathrm{E}$ & $\mathrm{E}$ & $\mathrm{E}$ & V & $\mathrm{E}$ & I & $\mathrm{V}$ & $\mathrm{E}$ & $\mathrm{E}$ & $\mathrm{E}$ & $\mathrm{E}$ & V & $\mathrm{V}$ & $\mathrm{E}$ & I \\
\hline$P_{4}$ & $\mathrm{~V}$ & V & $\mathrm{V}$ & $\mathrm{E}$ & $\mathrm{E}$ & $\mathrm{E}$ & I & $\mathrm{E}$ & $\mathrm{E}$ & I & $\mathrm{E}$ & $\mathrm{E}$ & $\mathrm{E}$ & $\mathrm{E}$ & I & V & I & $\mathrm{E}$ \\
\hline$P_{5}$ & I & $\mathrm{E}$ & $\mathrm{E}$ & $\mathrm{E}$ & $\mathrm{E}$ & $\mathrm{E}$ & $\mathrm{E}$ & $\mathrm{E}$ & $\mathrm{V}$ & $\mathrm{E}$ & $\mathrm{E}$ & $\mathrm{E}$ & $\mathrm{E}$ & $\mathrm{E}$ & M & I & V & V \\
\hline$P_{6}$ & I & M & $\mathrm{L}$ & $\mathrm{L}$ & $\mathrm{E}$ & I & I & $\mathrm{V}$ & $\mathrm{V}$ & V & V & I & $\mathrm{E}$ & $\mathrm{E}$ & $\mathrm{V}$ & $\mathrm{E}$ & $\mathrm{E}$ & $\mathrm{E}$ \\
\hline
\end{tabular}

Table 3: Participants' importance level expressed by triangular fuzzy numbers corresponding to the linguistic scale

\begin{tabular}{|l|l|l|l|l|l|l|l|l|l|l|l|l|l|l|l|}
\hline & \multicolumn{2}{|l|}{$\mathrm{E}_{1}$} & \multicolumn{2}{l|}{$\mathrm{E}_{2}$} & & \multicolumn{2}{|l|}{$\mathrm{E}_{15}$} & \multicolumn{2}{l|}{$\mathrm{E}_{18}$} \\
\hline & $\alpha$ & $\beta$ & $\gamma$ & $\alpha$ & $\beta$ & $\gamma$ & $\ldots$ & $\alpha$ & $\beta$ & $\gamma$ & $\ldots$ & $\alpha$ & $\beta$ & $\gamma$ \\
\hline$P_{1}$ & 2.5 & 3 & 3.5 & 1 & 1.5 & 2 & $\ldots$ & 2 & 2.5 & 3 & $\ldots$ & 0.5 & 1 & 1.5 \\
\hline$P_{2}$ & 1 & 1.5 & 2 & 0.5 & 1 & 1.5 & $\ldots$ & 0.5 & 1 & 1.5 & $\ldots$ & 1 & 1.5 & 2 \\
\hline$P_{3}$ & 2.5 & 3 & 3.5 & 1.5 & 2 & 2.5 & $\ldots$ & 2 & 2.5 & 3 & $\ldots$ & 1.5 & 2 & 2.5 \\
\hline$P_{4}$ & 2 & 2.5 & 3 & 2 & 2.5 & 3 & $\ldots$ & 1.5 & 2 & 2.5 & $\ldots$ & 2.5 & 3 & 3.5 \\
\hline$P_{5}$ & 1.5 & 2 & 2.5 & 2.5 & 3 & 3.5 & $\ldots$ & 1 & 1.5 & 2 & $\ldots$ & 2 & 2.5 & 3 \\
\hline$P_{6}$ & 1.5 & 2 & 2.5 & 1 & 1.5 & 2 & $\ldots$ & 2 & 2.5 & 3 & $\ldots$ & 2.5 & 3 & 3.5 \\
\hline
\end{tabular}

prevention of accidents at work. Later, the resulting data were analysed and the list of the main participants such as a developer $\left(P_{1}\right)$, a project leader $\left(P_{2}\right)$, a contractor $\left(P_{3}\right)$, OSH specialist $\left(P_{4}\right)$, OSH coordinator $\left(P_{5}\right)$ and a subcontractor $\left(P_{6}\right)$ was made. Then the experts were requested to rate the main participants according to linguistic significance scale. Finally, linguistic variables and converted to fuzzy numbers and ranks of influential persons determined.

Fuzzy participants' importance values defuzzified as follows (Figure 4):

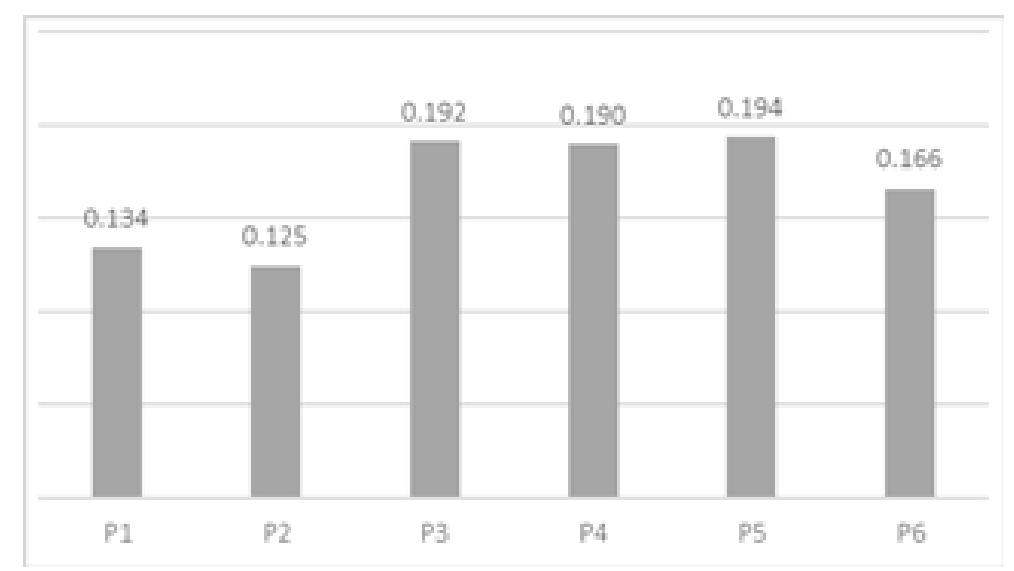

Figure 4: Final assessment of the influential person in sustainable prevention of accidents at work in construction

The last stage is a calculation of a relative importance index $(R I)$ of each considered participant (Figure 5):

$$
R I_{c}=\frac{w_{c}}{\max _{c} w_{c}}
$$




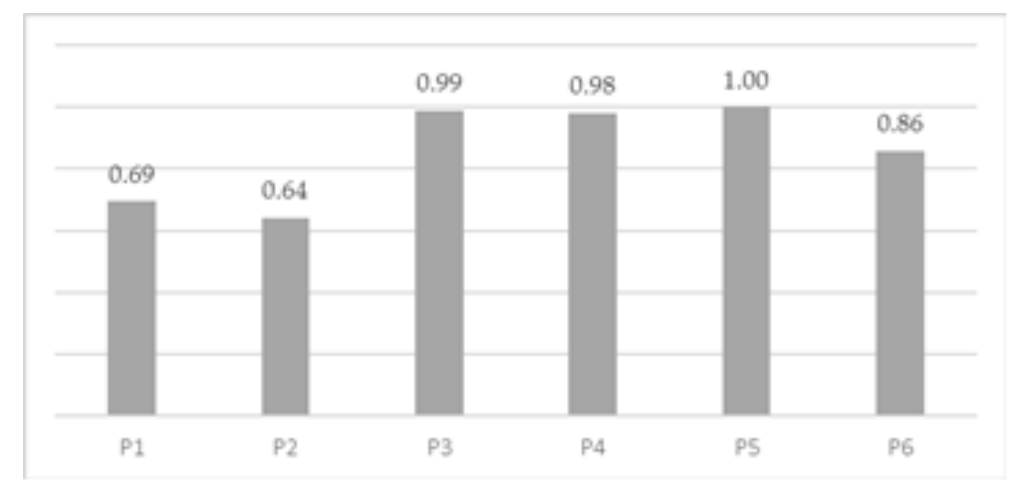

Figure 5: $R I$-relative importance of the influential person in sustainable prevention of accidents at work in the construction

\section{Results}

Key stakeholders, including the developer, the project leader, the OSH specialist, the OSH coordinator, the contractor, and the subcontractor, are the most influential persons who can prevent accidents at work in the SMEs construction sites.

The results of the investigation show that these stakeholders could have a positive impact on the sustainable prevention of accidents at work for SMEs. The importance of criteria has influence on their values in the multi-attribute utility function.

Besides, it is necessary to define values of quantitative and qualitative criteria (or people). The data identifying the most influential persons in the prevention of accidents at work are shown in Figure 5. According to the shown values of the relative importance $R I$, the main participants are divided into three groups. The most influential persons are the OSH coordinator $\left(P_{5}\right)$, the contractor $\left(P_{3}\right)$ and the OSH specialist $\left(P_{4}\right)$ whose $R I$ rates are the highest 1.00, 0.99 and 0.98 respectively. It means that the OSH coordinator, the OSH specialist and the contractor play a special role in the construction process, including $\mathrm{n}$ the areas of preventing an accident at work. Another influential person is the subcontractor $\left(P_{6}\right)$ at level 0.86 . He represents the second most influential group of persons. At the third importance level is the client $\left(P_{1}\right)$ and the project leader $\left(P_{2}\right)$ with the lowest $R I$ levels -0.69 and 0.64 respectively.

The above results show that leadership positions can have a positive impact on sustainable safety practices in the SME's construction enterprises. Managers such as the OSH coordinator, the OSH specialist and the contractor can also help to realise the targeted strategy of collectivism and consumer communication between a contractor and subcontractors.

\section{Conclusions}

The successful implementation of a sustainable modern construction project in a real environment is influenced by many complex procedural, social, economic, political and technological factors and affects various groups of people differently.

Therefore, the best solutions can be achieved by applying scientific methods involving a large amount of information and calculations. An important problem for each country is prevention of accidents at work in the SME's which dominate in the construction market.

Introducing necessary precautions on the construction sites prior to construction begins with an aim to ensure a safe and healthy environment is one of key tasks of building project leaders (stakeholders). Each participant of the construction process plays his own and specific role in the execution process of construction projects and stands against various risks. 
Their different attitudes, rights, abilities, and responsibilities in the prevention of accidents at work depends on education, work experience in management of construction projects, skills and knowledge of specific approaches to prevent accidents. Besides education, an ability to cope with risk is very important factors.

The developer, the project leader, the OSH specialist, the OSH coordinator, the contractor, and the subcontractor are the most influential persons who have the ability to an effective sustainable prevention of accidents at work in the construction.

The initial data in similar group decision-making approaches are presented by experts in words. Each of experts has own opinion about criteria values. The significance of expert estimations was assessed with the help of the modified fuzzy group Eckenrode's rating method. The proposed method is superior to conventional techniques because the proposed method has the capability to make group decisions in fuzzy environment. Therefore, fuzzy set theory is a powerful tool to solve such problems.

It is very important to know which of the project life cycle 's participants, depending on their position in the decision hierarchy, is the most influential on direct decisions, or on the choice of project management groups which can most effectively implement projects and supervise these processes.

It is also necessary to determine the most effective strategy for a sustainable development.

When designing a project team, the size, complexity, duration, type of the project and specific requirements for the stakeholders should be evaluated.

The research shows that the most influential persons in a sustainable prevention of accidents at work in the SME's construction enterprises rank as follows: the OSH coordinator, the contractor, the OSH specialist (rates from 1 to 0.98), the subcontractor (rates as 0.86), the client, and the project leader (rates 0.69 and 0.64 respectively). The model presented in this study is suitable for identifying and selecting key players and their influence or for determining the importance of criteria in the multi-criteria utility function. The results and findings will be expanded and used by future researchers.

\section{Bibliography}

[1] Allen, D. E.; McAleer, M., Singh, A. K. (2017); Risk measurement and risk modelling using applications of Vine copulas, Sustainability, 9(10), 1762, 2017.

[2] Barrett, M. (1914; . A comparison of the Order of Merit method and the method of Paired Comparisons. Psychological Review, 21(4), 278-294, 1914.

[3] Bartlett, C. J.; Heermann, E.; Rettig, S. (1960); A comparison of six different scaling techniques. The Journal of Social Psychology, 51(2), 343-348, 1960.

[4] Bejinariu, C.; Darabont, D. C.; Baciu, E. R.; Georgescu, I. S.; Bernevig-Sava, M. A.; Baciu, C. (2017); Considerations on Applying the Method for Assessing the Level of Safety at Work. Sustainability, 9(7), 1263, 2017.

[5] Bock, R.D.; Jones, L.V. (1963); The Measurement and Prediction of Judgemental Response: Statistical Methods. U. S. Army Test and Evaluation Command Project 7-S-0901-OIE. Psychometric Laboratory, University of North Carolina, 1963.

[6] Bonenberg, W.; Kapliński, O. (2018); The Architect and the Paradigms of Sustainable Development: A Review of Dilemmas. Sustainability, 10(1), 100, 2018. 
[7] Borg, G. (1970); Perceived exertion as an indicator of somatic stress. Scandinavian Journal of Rehabilitation Medicine, 2(2), 92-98, 1970.

[8] Buckley, J. J. (1984); The multiple judge, multiple criteria ranking problem: a fuzzy set approach. Fuzzy Sets Syst, 13, 25-37, 1984.

[9] Buel, W.D. (1960); A simplification of Hay's method of recording paired comparisons. Journal of Applied Psychology, 44(5), 347-348, 1960.

[10] Chatterjee, K.; Pamucar, D.; Zavadskas, E. K. (2018); Evaluating the performance of suppliers based on using the R'AMATEL-MAIRCA method for green supply chain implementation in electronics industry Journal of Cleaner Production, 184, 101-129, 2018.

[11] Churchman, C. W.; Ackoff, R.L.; Arnoff, E.L. (1957); Introduction to Operations Research. New York: Wiley. 1957.

[12] Debnath, J.; Biswas, A.; Sivan, P.; Sen, K.N.; Sahu, S. (2016); Fuzzy inference model for assessing occupational risks in construction sites, International Journal of Industrial Ergonomics, 55, 114-128, 2016.

[13] Delbecq, A.L.; VandeVen, A.H. (1971); A Group Process Model for Problem Identification and Program Planning. Journal of Applied Behavioral Science, 7, 466-491, 1971.

[14] Dubois, D.; Prade, H. (1978); Operations on fuzzy numbers. International Journal of Systems Science, 9(6), 613-626, 1978.

[15] Dzitac, I.; Filip, F.G.; Manolescu, M.J.(2017); Fuzzy Logic Is Not Fuzzy: World-renowned Computer Scientist Lotfi A. Zadeh, International Journal of Computers Communications \& Control, 12(6), 748-789, 2017.

[16] Eckenrode, R.T. (1965); Weighting multiple criteria. Management Science, 12(3), 180-192, 1965.

[17] Eizenberg, E.; Jabareen, Y. (2017); Social sustainability: A new conceptual framework. Sustainability, 9(1), 68, 2017.

[18] Finkbeiner, M.; Schau, E. M.; Lehmann, A.; Traverso, M. (2010); Towards life cycle sustainability assessment. Sustainability, 2, 3309-3322, 2010.

[19] Gerbec, M. (2017); Safety change management-A new method for integrated management of organizational and technical changes, Safety Science, 100, 225-234, 2017.

[20] Ghassemi, A.; Darvishpour, A. (2018); A novel approach for risk evaluation and risk response planning in a geothermal drilling project using DEMATEL and fuzzy ANP. Decision Science Letters, 7(3), 225-242, 2018.

[21] Ginevicius, R. (2011); A new determining method for the criteria weights in multicriteria evaluation, International Journal of Information Technology $\&$ Decision Making, 10(6), 1067-1095, 2011.

[22] Grassi, A.; Gamberini, R.; Mora, C.; Rimini, B. (2009); A fuzzy multi-attribute model for risk evaluation in workplaces. Safety Science, 47(5), 707-716, 2009.

[23] Hasle, P.; Kines, P.; Andersen, L.P. (2009); Small enterprise owners' accident causation, attribution and prevention. Safety Science, 47(1), 9-19, 2009. 
A Fuzzy Group Decision-making Model for Determining the

Most Influential Persons in the Sustainable Prevention of

[24] Hinze, J.; Thurman, S.; Wehle, A. (2013); Leading indicators of construction safety performance. Safety Science, 51(1), 23-28, 2013.

[25] Hoła, B.; Szóstak, M. (2017); The methodology of analysing the accident rate in the construction industry. In Procedia Engineering, Proceedings of Modern Building Materials, Structures and Techniques (MBMST) 2016, Vilnius, Lithuania; Juozapaitis A., Daniūnas A., Zavadskas E. K., 172, 355-362, 2017.

[26] Idrees, M. D.; Hafeez, M.; Kim, J.Y. (2017); Workers' age and the impact of psychological factors on the perception of safety at construction sites, Sustainability, 9(5), 745, 2017.

[27] Jiang, W.; Zhao, X.; Ni, J. (2017); The impact of transformational leadership on employee sustainable performance: The mediating role of organizational citizenship behavior. Sustainability, 9(9), 1567, 2017.

[28] Keršuliene, V.; Zavadskas, E.K.; Turskis, Z. (2010); Selection of rational dispute resolution method by applying new step-wise weight assessment ratio analysis (SWARA). Journal of business economics and management, 11(2), 243-258, 2010.

[29] Keshavarz Ghorabaee, M.; Zavadskas, E. K.; Olfat, L.; Turskis, Z. (2015); Multi-criteria inventory classification using a new method of evaluation based on distance from average solution (EDAS). Informatica, 26(3), 435-451, 2015.

[30] Keshavarz-Ghorabaee, M.; Amiri, M.; Zavadskas, E.K.; Turskis, Z.; Antucheviciene, J. (2018); An Extended Step-Wise Weight Assessment Ratio Analysis with Symmetric Interval Type-2 Fuzzy Sets for Determining the Subjective Weights of Criteria in Multi-Criteria Decision-Making Problems. Symmetry, 10, 91, 2018.

[31] Khasreen, M. M.; Banfill, P.F.; Menzies, G.F. (2009); Life-cycle assessment and the environmental impact of buildings: a review. Sustainability, 1(3), 674-701, 2009.

[32] Leberling, H. (1981); On finding compromise solution in multi-criteria problems using the fuzzy min-operator. Fuzzy Sets Syst, 6, 105-110, 1981.

[33] Leung, M.; Chan, I.Y.S.; Yu, J. (2012); Preventing construction worker injury incidents through the management of personal stress and organizational stressors. Accident Analysis and Prevention, 48, 156-166, 2012.

[34] Liao, P.C.; Liu, B.; Wang, Y.; Wang, X.; Ganbat, T. (2017); Work paradigm as a moderator between cognitive factors and behaviors-A comparison of mechanical and rebar workers. KSCE Journal of Civil Engineering, 21(7), 272814-2525, 2017.

[35] Likert, R. (1932); A technique for the measurement of attitudes. Archives of Psychology, 140(22), 1-55, 1932.

[36] Lingard, H.; Wakefield, R.; Cashin, P. (2011); The development and testing of a hierarchical measure of project OHS performance, Eng., Constr. Arch. Manage, 18(1), 30-49, 2011.

[37] Linstone, H.A.; Turoff, M. (2002); The Delphi Method: Techniques and Applications, Addison-Wesley Publishing Company: Advanced Book Program, Vol. 18, 2002.

[38] Liu, H. T.; Tsai, Y. L. (2012); A fuzzy risk assessment approach for occupational hazards in the construction industry, Safety Science, 50(4), 1067-1078, 2012. 
[39] Liu, Y.J.; Chen, J.L.; Cheng, S.Y.; Hsu, M.T.; Wang, C.H. (2014); Evaluation of safety performance in process industries. Process Safety Progress, 33(2), 166-171, 2014.

[40] Maliene, V.; Dixon-Gough, R.; Malys, N. (2018); Dispersion of relative importance values contributes to the ranking uncertainty: Sensitivity analysis of Multiple Criteria DecisionMaking methods, Applied Soft Computing Journal, 67, 286-298, 2018.

[41] McSween, T.; Moran, D. J. (2017); Assessing and Preventing Serious Incidents with Behavioral Science: Enhancing Heinrich's Triangle for the 21st Century. Journal of Organizational Behavior Management, 37(3-4), 283-300, 2017.

[42] Morelli, J. (2011); Environmental Sustainability: A Definition for Environmental Professionals. Journal of Environmental Sustainability, 1(1), 2, 2011.

[43] Moura, R.; Beer, M.; Patelli, E.; Lewis, J.; Knoll, F. (2017); Learning from accidents: Interactions between human factors, technology and organisations as a central element to validate risk studies, Safety Science, 99, 196-214, 2017.

[44] Nakhaei, J.; Bitarafan, M.; Lale Arefi, S.; Kapliński, O. (2016); Model for rapid assessment of vulnerability of office buildings to blast using SWARA and SMART methods (a case study of Swiss Re Tower). Journal of Civil Engineering and Management, 22(6), 831-843, 2016 .

[45] Papazoglou, I.A.; Aneziris, O.N.; Bellamy, L.J.; Ale, B.J.M.; Oh, J. (2017); Multi-hazard multi-person quantitative occupational risk model and risk management, Reliability Engineering ES System Safety, 167, 310-326, 2017.

[46] Pasman, H.J.; Rogers, W.J.; Mannan, M.S. (2017); Risk assessment: What is it worth? Shall we just do away with it, or can it do a better job? Safety Science, 99, 140-155, 2017.

[47] Peldschus, F.; Zavadskas, E. K.; Turskis, Z.; Tamosaitiene, J. (2010); Sustainable assessment of construction site by applying game theory. Inzinerine Ekonomika-Engineering Economics, 21(3), 223-237, 2010.

[48] Ruzgys, A.; Volvaciovas, R.; Ignatavicius, C.; Turskis, Z. (2014); Integrated evaluation of external wall Insulation in residential buildings using SWARA-TODIM MCDM method. Journal of Civil Engineering and Management, 20(1), 103-110, 2014.

[49] Saaty, T. L. (1980); The Analytic Hierarchy Process: Planning, Priority Setting, Resources Allocation. New York: McGraw, 1980.

[50] Saaty, T. L. (1996); Decision Making with Dependence and Feedback: The Analytic Network Process, Pittsburgh, Pennsylvania: RWS Publications, 1996.

[51] Šaparauskas, J.; Zavadskas, E. K.; Turskis, Z. (2011); Selection of facade's alternatives of commercial and public buildings based on multiple criteria. International Journal of Strategic Property Management, 15(2), 189-203, 2011.

[52] Seker, S.; Zavadskas, E. K. (2017); Application of Fuzzy DEMATEL Method for analyzing occupational risks on construction sites, Sustainability, 9(11), 2083, 2017.

[53] Sinclair, R. C.; Cunningham, T.R.; Schulte, P. A. (2013); A model for occupational safety and health intervention diffusion to small businesses. Am. J. Ind. Med., 56(12), 1442-1451, 2013. 
A Fuzzy Group Decision-making Model for Determining the

Most Influential Persons in the Sustainable Prevention of Accidents in the Construction SMEs

[54] Sinelnikov, S.; Inouye, J.; Kerper, S. (2015); Using leading indicators to measure occupational health and safety performance. Safety Science, 72, 240-248, 2015.

[55] Sivilevičius, H.; Zavadskas, E.K.; Turskis, Z. (2008); Quality attributes and complex assessment methodology of the asphalt mixing plant, Baltic Journal of Road $\&$ Bridge Engineering, 3(3), 161-166, 2008.

[56] Stankiuviene, A.; Cyras, P.; Vakriniene, S. (2008); Risk identification in technical regulation. The 7th International Conference Environmental Engineering, Selected Papers, ISBN, 9789955-28-256-3, Vilnius Gediminas Technical University Publishing House: Technika, 341$349,2008$.

[57] Stoklasa, J., Talášek, T., Kubatova, J., Seitlova, K. (2017). Likert Scales in Group Multiplecriteria Evaluation. Journal of Multiple-Valued Logic \& Soft Computing, 29(5), 425-440, 2017.

[58] ك̌ukys, R.; Čyras, P.; Šakenaitè, J. (2011); Economical loss due to non-compliance with requirements for personnel safety and health in Lithuanian construction sector, Journal of Civil Engineering and Management, 17(2), 168-176, 2011.

[59] Sun, M.; Zheng, Z.; Gang, L. (2018); Uncertainty Analysis of the Estimated Risk in Formal Safety Assessment, Sustainability, 10, 321, 2018.

[60] Tremblaya, A.; Badri, A. (2018); Assessment of occupational health and safety performance evaluation tools: State of the art and challenges for small and medium-sized enterprises, Safety Science, 101, 260-267, 2018.

[61] Turskis, Z.; Juodagalvienè, B. (2016); A novel hybrid multi-criteria decision-making model to assess a stairs shape for dwelling houses, Journal of Civil Engineering and Management, 22:8, 1078-1087, 2016.

[62] Turskis, Z.; Lazauskas, M.; Zavadskas, E. K. (2012); Fuzzy multiple criteria assessment of construction site alternatives for non-hazardous waste incineration plant in Vilnius city, applying ARAS-F and AHP methods, Journal of Environmental Engineering and Landscape Management, 20(2), 110-120, 2012.

[63] Van Laarhoven, P.J.M.; Pedrycz, W. (1983); A fuzzy extension of Saaty's priority theory, Fuzzy Sets and Systems, 11(1-3), 229-241, 1983.

[64] Velleman, P. F.; Wilkinson, L. (1993); Nominal, ordinal, interval, and ratio typologies are misleading, The American Statistician, 47(1), 65-72, 1993.

[65] Whinney, M. D. (1971); Christopher Wren, Praeger Publishers: New York, 1971.

[66] Yau, B. (2014); Occupational safety culture index e Measuring the community and employees awareness, attitude and knowledge towards workplace safety and health in Hong Kong [power point slides], XX World Congress on Safety and Health at Work 2014 e Global Forum for Prevention. Frankfurt (Germany), 2014.

[67] Yilmaz, F.; Alp, S. (2016); Underlying factors of occupational accidents: the case of Turkey, Open Journal of Safety Science and Technology, 6, 1-10, 2016.

[68] Yoon, K.; Hwang, C. (1995); Multiple Attribute Decision Making: An introduction; Sage Publications, London, 1995. 
[69] Zadeh, L. A. (1965); Fuzzy sets. Inf Control, 8, 338-353, 1965.

[70] Zagorskas, J.; Zavadskas, E. K.; Turskis, Z.; Burinskienè, M.; Blumberga, A.; Blumberga, D. (2014); Thermal insulation alternatives of historic brick buildings in Baltic Sea Region. Energy and buildings , 78, 35-42, 2014.

[71] Zavadskas, E. K.; Antuchevičienè, J.; Šaparauskas, J.; Turskis, Z. (2013); MCDM methods WASPAS and MULTIMOORA: verification of robustness of methods when assessing alternative solutions, Economic Computation and Economic Cybernetics Studies and Research, $47(2), 5-20,2013$.

[72] Zavadskas, E. K.; Turskis, Z.; Volvačiovas, R.; Kildienè, S. (2013); Multi-criteria assessment model of technologies, Studies in Informatics and Control, 22(4), 249-258, 2013.

[73] Zavadskas, E. K.; Vilutienè, T. (2006); A multiple criteria evaluation of multi-family apartment block's maintenance contractors: I-Model for maintenance contractor evaluation and the determination of its selection criteria, Building and environment, 41(5), 621-632, 2006.

[74] Zavadskas, E. K.; Vilutienè, T.; Turskis, Z.; Šaparauskas, J. (2014); Multi-criteria analysis of Projects' performance in construction, Archives of Civil and Mechanical Engineering, 14(1), 114-121, 2014.

[75] Zavadskas, E.K.; Kaklauskas, A.; Turskis, Z.; Kalibatas, D. (2009); An approach to multiattribute assessment of indoor environment before and after refurbishment of dwellings, Journal of Environmental Engineering and Landscape Management, 17(1), 5-11, 2009.

[76] Zhou, Z.; Goh, Y.M.; Li, Q. (2015); Overview and analysis of safety management studies in the construction industry, Safety Science, 72, 337-350, 2015. 